\title{
Contragenealogías del silencio. Una propuesta desde los estudios culturales feministas
}

\section{Artículo de investigación}

\section{María Teresa Garzón Martínez}

Autora invitada

Cesmeca-Unicach, México

maria.garzon@unicach.mx

Recibido: 15 de noviembre de 2018

Aceptado: 10 de enero de 2019

Cómo citar este artículo: Garzón Martínez, María Teresa (2019).Contragenealogías del silencio. Una propuesta desde los estudios culturales feministas. Calle 14: revista de investigación en el campo del arte 14(26). pp. 254-268. DOI: https://doi.org/10.14483/21450706.15002

\section{(c) (1)}

https://creativecommons.org/licenses/by/4.0/deed.es 


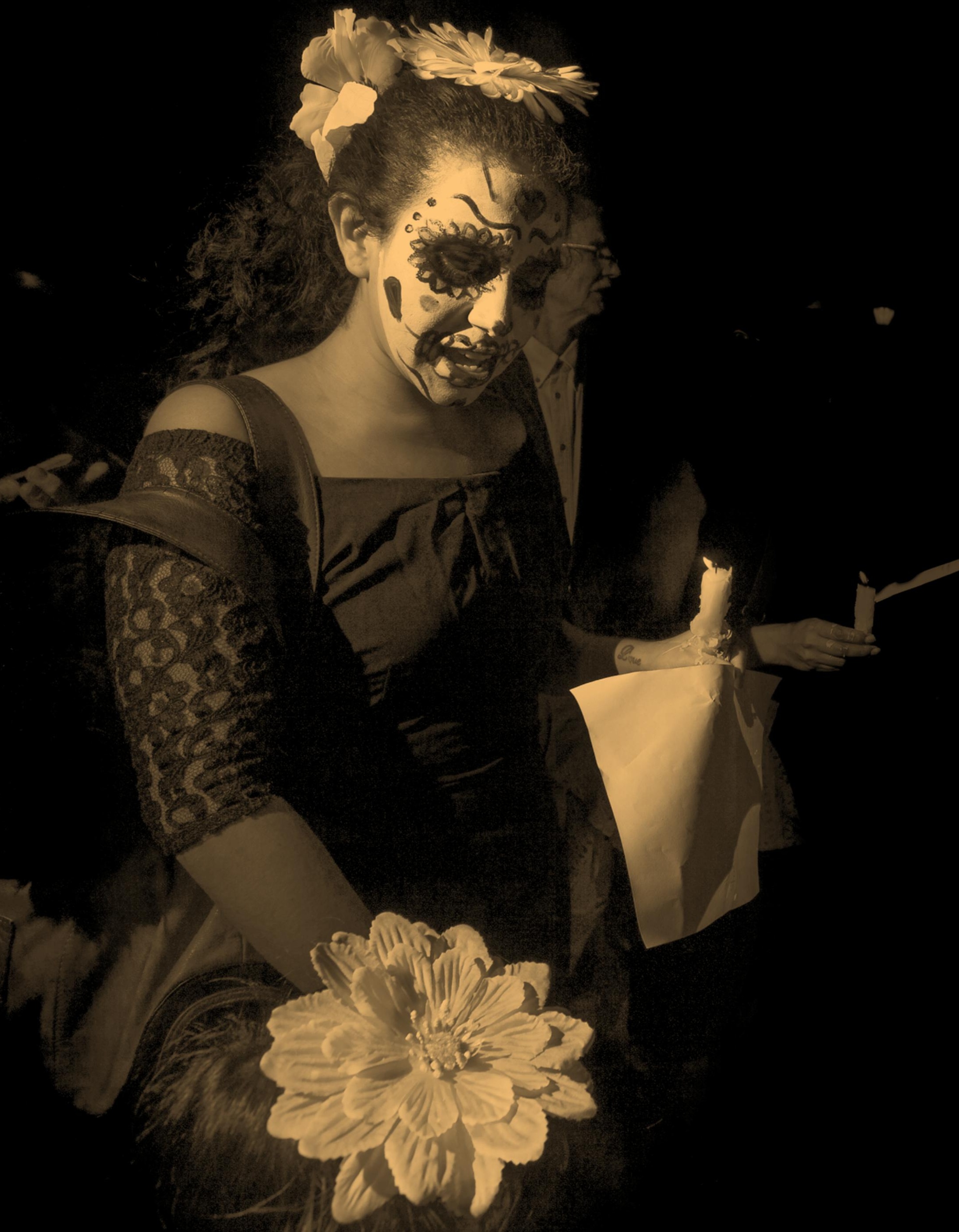




\title{
Resumen
}

El presente artículo de reflexión es una deriva en torno a la pregunta sobre si es posible hacer genealogía desde los estudios culturales y feministas o, si mejor, el método al que nos debemos abocar, en la actualidad, cuando preguntamos por las existencias de las mujeres, bajo condiciones de imposibilidad, debe ser contragenealógico. Partiendo de la experiencia de investigar el personaje de La Llorona, su lamento, su silencio, el artículo presenta tres discusiones cardinales: cómo interpretar el silencio de la subalterna, cómo construir un archivo de aquello que no tiene huella y, en consecuencia, qué es afrontar el fracaso cuando se hacen estudios feministas y culturales.

\section{Palabras clave}

Genealogía; contragenealogía; archivo; fracaso; silencio; Llorona

\section{Countergenealogies of Silence. A Proposal From Feminist Cultural Studies}

\begin{abstract}
The present article of reflection is derived from the question about whether it is possible to carry out genealogies in cultural and feminist studies, or if it is better, when we ask today-under conditions of impossibility-about the lives of women, that the method should be countergenealogical. Based on the experience of investigating the character of La Llorona, her lamentation and her silence, the article raises three main issues: how to interpret the silence of one who is subordinate; how to build an archive of that which has no trace and, consequently, what does it mean to face failure when doing feminist and cultural studies.
\end{abstract}

\section{Keywords}

Genealogy; countergenealogy; archive; failure; silence; La Llorona

Les généalogies du silence. Une proposition à partir des études culturelles féministes

\section{Résumé}

Le présent article de réflexion découle de la question de savoir s'il est possible de réaliser des généalogies dans les études culturelles et féministes, ou s'il vaut mieux, quand on pose des questions aujourd'hui — dans des conditions d'impossibilité — sur la vie des femmes, que la méthode soit plutôt contre-généalogique. À partir de l'expérience d'enquêter sur le personnage de La Llorona, sur ses lamentations et son silence, l'article soulève trois questions principales: comment interpréter le silence de ce qui est subordonné ; comment construire des archives de ce qui n'a aucune trace et, par conséquent, que signifie faire face à un échec lorsqu'on effectue des études féministes et culturelles.

\section{Mots clés}

Généalogie ; contre-généalogie ; archive ; échec ; silence ; La Llorona

\section{Resumo}

O presente artigo de reflexão é derivado da questão sobre se é possível realizar genealogias em estudos culturais e feministas, ou se é melhor, quando perguntamos hoje - sob condições de impossibilidade - sobre a vida das mulheres, um método contra-genético. Com base na experiência de investigar o caráter de La Llorona, seu lamento e seu silêncio, o artigo levanta três questões principais: como interpretar o silêncio de quem é subordinado; como construir um 
arquivo daquilo que não tem rastro e, consequentemente, o que significa enfrentar o fracasso ao fazer estudos feministas e culturais.

\section{Palavras-chave}

Genealogia; contragenealogia; arquivo; falha; silêncio; La Llorona

\section{Maillallachiska}

Kai kilsaka allilla iuiariipi kauanchimi tapungapa allikanchu rurangapa geneologia iachachidiru uasimanda cultural uarmikunamanda $u$ allikanchu kauangapa kai kunaura tapuura uarmikunamanda kaugsaskamanda, antiva parlumanda uakasike uarmimanda, paipa kijarii, paipa upalla kai, kai kilkaska kauachi kimsa rimaikuna cardinalkuna: imasa kauare upallape chi subalternoa, imasa rurangapa sug uakachidiru mana taridiru, chasak kauangapa mana allika ruraura iachaikuna uarmikunamanda i culturalkuna.

\section{Rimangapa Ministidukuna}

Geneologia; contrageneologia; uakachidiru; mana allikai; upalla,uakasiki 
Armar / desarmar / montar / desmontar palabras no es un juego del que se salga indemne o sin cicatrices, es una apuesta arriesgada por hacer correr la sangre

valeria flores

De herencia focultiana —es Michel Foucault quien retoma e innova a manera de fragmentos filosóficos en talleres históricos las pistas dejadas por Nietzsche-, la genealogía es, ante todo, una propuesta creativa, metodológica y política que nos lleva a historizar las prácticas, en concreto, del pasado que dan como resultado un "ser", un "sentir", un "desear", un "hacer" en el presente, siguiendo ciertas reglas, relaciones de poder, efectos de universalización y luchas por la hegemonía y la emancipación. La genealogía, en consecuencia, no es la historia o una historia de las ideas o una historia de los objetos, sino una forma de "contra-historia" que busca no los orígenes de nada, sino la emergencia, en algún momento del pasado, de formas de experiencia del mundo - modos de ser - que se mantienen presentes en nuestro ahora y cuyo efecto es la producción de sujetos y su operar en coordenadas de relaciones de poder. En suma, en palabras del gran genealogista latinoamericano Santiago Castro-Gómez, la genealogía es un esfuerzo por: "historizarlo siempre todo, en los intersticios entre la filosofía y la historia, respondiendo a una propuesta particular de escribir la historia que viene animada por un interés emancipatorio" (2013, s.p).

Bajo estos parámetros, la genealogía es una vía posible para responder quiénes somos y cómo llegamos a ser lo que somos, pero no en términos abstractos o universales, más bien como fruto de condiciones de posibilidad dadas en circunstancias específicas, localizadas en términos de tiempo, espacio y poder (Castro-Gómez, 2012). No obstante, si la pregunta que anima la genealogía no es por el "llegar a ser", sino por el "no llegar a ser", esto es por las condiciones de posibilidad que producen la imposibilidad, la no existencia, la división ontológica entre el ser y el no ser, entre el archivo y su silencio, entre la huella y su borradura, entonces: ¿Qué territorio debemos pisar o no pisar pues "pies para qué los quiero si tengo alas para volar" ? ¿A qué nos lleva litigar contra nuestras propias herramientas de

1 Célebre frase de la pintora mexicana Frida Kahlo, escrita en 1953, en su diario personal, un año antes de su muerte cuando le fue amputada la pierna derecha. producción de conocimiento, escribir contra sí misma?² ¿Cómo construir genealogías del nosotras desde el no? En este punto, es posible que la genealogía no sea un método feminista, pues las mujeres como constructo real, corporal y digno en Occidente, a pesar de nuestras diversas presencias discursivas, imaginarias, simbólicas, no estamos siendo posibles ni siquiera como negación, ya no. Por ello, hoy morimos de dolor. ${ }^{3}$ Así, tal vez, el método feminista para encontrarnos a nosotras mismas, para escribir nuestras contra-historias haciendo correr la sangre en busca del más allá de la justicia es, más bien, contragenealógico.

Las siguientes letras son una deriva que habla del fracaso, en especial de eso. Quiero reflexionar aquí sobre mi propio hacer creativo, académico y político intelectual y cómo el mismo me ha sembrado esta duda sobre las opciones de hacer investigación feminista desde la genealogía. Así, guiada por algunas ideas que he construido en mi investigación: "La Llorona déjà vu y otros silencios. Silencio, subalternidad y colonialidad", 4 en la cual se explora el silencio analizando la figura de La Llorona, en diferentes expresiones de la cultura popular latinoamericana, a continuación expongo algunas discusiones a propósito con la conciencia de que cuando hacemos estudios culturales feministas no solo estamos haciendo apuestas "sin garantías", también estamos viviendo el fracaso de las preguntas sin respuestas, el errar del pensamiento, la letra como cicatriz. Fracaso, por lo tanto, porque una contragenealogía del silencio nos obliga a aceptar que: "la complejidad del mundo simplemente significaba que se tendría que estar siempre trabajando, seguir teorizando, aceptando el fracaso como parte del camino para contar mejores historias" (Grossberg, 2009, p. 26). Y más cuando nos ubicamos en un contexto geopolítico, al sur de México -Chiapas-,

\footnotetext{
$2 \quad$ A propósito, se puede consultar mi artículo: "Oximoron. Blanquitud y feminismo descolonial en la Abya Yala", publicado en la revista Descentrada, cuyos datos se reseñan en la bibliografía. 3 Hace referencia al feminicidio de Lucía Pérez, joven argentina de 16 años de edad, en el año 2016, en Mar del Plata, Argentina. Lucía fue drogada, violada y empalada hasta llegar a experimentar un "shock cardíaco similar al que sufre una persona bajo tortura extrema". Lucía murió, literalmente, de dolor. Sus agresores -Matías Farías y Juan Pablo Offidani- fueron sentenciados, por el tribunal de Mar del Plata, a 8 años de prisión por el delito de tenencia y comercialización de estupefacientes, negando una sentencia por acceso carnal violento y feminicidio. A propósito, se puede consultar: «https://www.lainformacion.com/mundo/Violada-drogada-empaladaconmociona-Argentina_0_962604959.html»

$4 \quad$ Parte de la investigación se puede visitar en el ensayo: "Nunca regalé el llanto. Silencio, gemido y re(ex)sistencia en la Llorona", cuyos datos se reseñan en la bibliografía.
} 


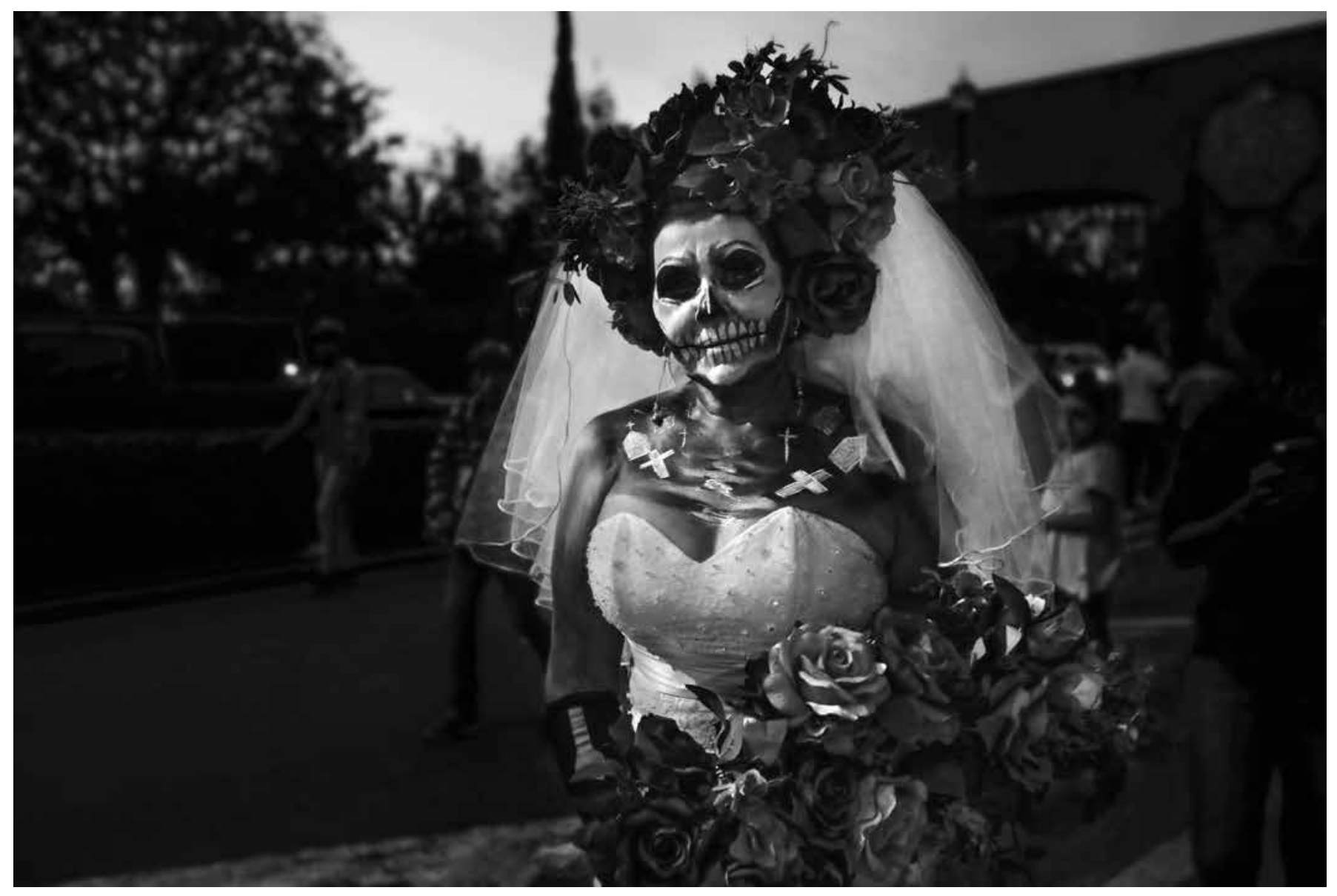

Imagen 1. Efraín Ascencio Cedillo (2017). Tlaquepaque (Jalisco, México). Cortesía del artista.

donde la visión hegemónica de los estudios feministas -monopolizada por ciertas feministas históricas que resienten el cambio generacional y trabajan en contra de él- se asientan en la antropología más disciplinar y colonial, desde donde se hacen circular versiones que dicen que el trabajo del feminismo con la cultura es pura mierda y que no importa cuántas muertas contemos, sino cuánto dinero hagamos con ello.

\section{La pregunta de Spivak}

Gayatri Spivak, en su famoso artículo: “¿Puede hablar el subalterno?" (1988/2003), ${ }^{5}$ lanza una pregunta fundamental para la reflexión feminista descolonial hoy; en especial, cuando intentamos hacer genealogía de las prácticas culturales de las mujeres desafiando, en mi caso, la historia construida desde la crítica literaria feminista de los años ochenta y noventa del siglo

5 Publicado originalmente en: Cary Nelson y Larry Grossberg, (eds.) 1988. Marxism and the interpretation of Culture, Chicago: University of Illinois Press. pasado, en Latinoamérica -en un contexto tiempoespacial específico en donde esto, no obstante, fue fundamental-, que instituyó la idea de que las escritoras hemos sido "borradas" de la historia de la literatura, silenciadas o, en el mejor de los casos, hemos sido obligadas a transvestirnos con seudónimos masculinos. ¿Podrá entonces una escritora "ser" escritora desde su propio silenciamiento? ¿Pueden sobrevivir las letras a su propia tachadura? ¿Qué formas de paradoja genera este borramiento ${ }^{6}$ Claro, la pregunta sobre si el subalterno puede hablar y su consecuente respuesta no deben ser tomadas de manera literal:

Es claro que el subalterno habla físicamente; sin embargo, su habla no adquiere estatus dialógico —en el sentido que plantea Bakhtin-, esto es, el subalterno no es un sujeto que ocupa una posición discursiva desde la que pueda hablar o responder.

6 A propósito, se puede consultar mi artículo: "Montserrat Ordóñez y la escritora excluida". En: Garzón Martínez, María Teresa; Mendoza, Nydia Constanza (2007). Mundos en disputa. Intervenciones en Estudios Culturales, Bogotá: Pontificia Universidad Javeriana, Pensar. 
Como indica Spivak, es el espacio en blanco entre las palabras, aunque el que se le silencie no significa que no exista (Giraldo, 2003, p. 298).

La mujer, al ser la subalterna del subalterno, sufre su mudez de manera más dramática, continúa Spivak. En efecto, parafraseando a la autora se puede afirmar que dentro del itinerario suprimido del sujeto subalterno, la pista de la diferencia sexual está doblemente suprimida. Indudablemente: "Si en el contexto de la producción colonial el subalterno no tiene historia y no puede hablar, el subalterno como femenino está aún más profundamente en tinieblas" (Spivak, 2003, p. 328). Para indagar sobre esto, Spivak analiza la abolición británica del sacrificio de viudas, en 1829, y desde allí empieza a "trazar" una historia:

Mientras uno va revisando los nombres grotescamente mal transcritos de estas mujeres, las viudas sacrificadas, en los informes de policía incluidos en los registros de la Compañía de las Indias Orientales, uno no puede poner en conjunto una "voz". Lo más que uno puede sentir es la inmensa heterogeneidad atravesando tal relación esquelética e ignorante -las castas, por ejemplo, son descritas regularmente como tribus-. Enfrentada a las frases dialécticamente entrelazadas que son construibles tales como "Hombres blancos están salvando mujeres cafés de hombres cafés" y "Las mujeres deseaban morir", la mujer intelectual poscolonial hace una pregunta de simple semiosis, ¿qué significa esto?, y empieza a trazar una historia (2003, p. 344).

El sati era un ritual antiguo - data de antes del siglo XVII - que consiste en que una vez muerto el "esposo", la "viuda" debe incinerarse en su pila funeraria: "La viuda hindú asciende a la pira del esposo muerto y se inmola a sí misma sobre ella. Este es el sacrificio de la viuda. (La transcripción convencional de la palabra sánscrita para viuda podría ser sati. Los británicos coloniales tempranos la transcribieron como suttee). El rito no era practicado universalmente y no tenía una fijación de casta o de clase" (Spivak, 2003, p. 344). En efecto, no todas las viudas pueden dar el paso "mortal", pues aquellas que están menstruando lo tienen

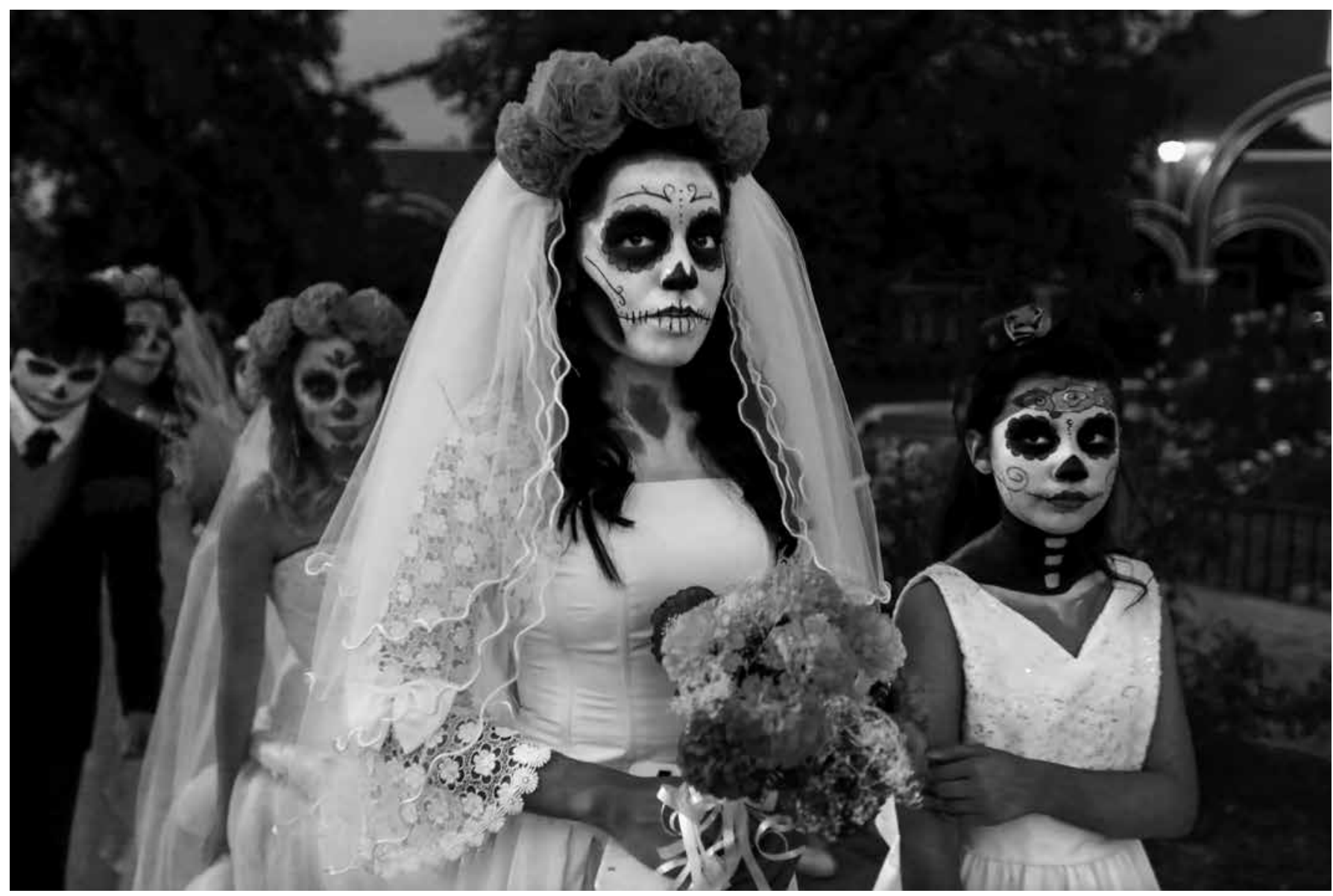

Imagen 2. Efraín Ascencio Cedillo (2017). Tlaquepaque (Jalisco, México). Cortesía del artista. 
prohibido. También existen pobres evidencias que dicen que una "viuda" puede negarse al ritual sufriendo un castigo cultural, un tipo especial de penitencia por ello. Estudiando el Dharmasastra, las escrituras sagradas de soporte, y el Rig-Veda, doctrina de alabanza, Spivak da cuenta de cómo, en el caso hindú, el sati —siempre un tema muy complejo y controvertido- no era considerado suicidio, pues en él no hay un yo conciencia o una identidad fenomenológica, o sea, no existe un "yo" y un "tú", por lo que este es un ritual que implica un acto de libre albedrío, ya que con ello las "mujeres" pueden inscribirse de manera efectiva en el ciclo eterno del renacimiento. Habría que preguntarse aquí, con el trabajo de Oyèrónké Oyèwùmi (La invención de las mujeres, 2017), si es correcto hablar de "mujeres" en la India pre-ocupación.

No obstante, en el siglo XIX, la administración colonial británica penaliza el ritual porque el mismo implica varios crímenes según su versión: asesinato, porque se mata al yo; infanticidio, porque se abandona a las crías; abandono letal, porque se deja a la gente vieja sin protección. Así: “el dudoso lugar del libre albedrío del sujeto sexuado constituido como mujer fue exitosamente borrado. No hay itinerario que podamos trazar de nuevo aquí" (Spivak, 2003, p. 351). En consecuencia, ese libre albedrío del que se habla en la versión hindú, donde las mujeres "realmente deseaban morir", queda borrado en medio de la tarea de "civilizar", donde los "hombres blancos, [buscan] salvar mujeres cafés de hombres cafés". Bajo estas condiciones, ¿puede la subalterna hablar? A todas luces, la respuesta es negativa: no existe una versión femenina del sati, mucho menos una versión lésbica. Tampoco existe una explicación feminista del ritual. De las viudas inmoladas solo quedan algunos registros de sus nombres, pero no más.

En este punto, el reto para Spivak se configura en construir la genealogía de esa mudez, de ese espacio en blanco entre las palabras. Sin embargo, tal empresa es imposible en el sentido que: "la tarea de recuperar un sujeto - sexualmente- subalterno se pierde en una textualidad institucional en su origen arcaico" (Spivak, 2003, p. 354). Si esto es así, ¿cuál es la opción? Partiendo del silencio de la subalterna, de lo que es menos que una huella, Spivak formula pistas para la configuración de una contragenealogía del silencio a través de la reconstrucción de la historia de Bhuvaneswari Bhaduri, una joven de dieciséis años, que se cuelga en el modesto apartamento de su padre en el norte de Calcuta, en 1926. El suicidio es un rompecabezas puesto que, como la chica está menstruando en ese momento, claramente no se trata de un caso de embarazo ilícito. Diez años después, se descubre que la chica en cuestión es miembro de uno de los muchos grupos implicados en la lucha armada por la independencia de India. Incapaz de cometer un homicidio estratégicamente necesario para la causa, Bhuvaneswari opta por suicidarse. A sabiendas de que su muerte será diagnosticada como producto de una pasión ilegítima, ella espera su periodo para morir en luna.

A través de esta historia, Spivak se pregunta si el acto de Bhuvaneswari es una escritura intervencionista del antiguo sati y su respuesta es positiva. No solo Bhuvaneswari "interviene" el sati retando la prohibición de acceder al ritual si se está menstruando, sino que escribe su "contra-historia" con su propia sangre menstrual. ¿Qué silencio es este hecho de muerte? ¿Cuál contragenealogía puede empezar por la gota de sangre menstrual? Como es obvio, y lo he dicho antes, el reto presente no es inventar un nuevo discurso para una nueva voz, sino mostrar la conformación contragenealógica de la mudez, de la violencia que le impregna y que (todavía) habita en nosotras (González Abrieska, Mendiola, 2010, en Garzón, 2016, p. 88). En consecuencia, es posible que estemos obligadas a encontrar ese punto histórico en el cual contra-historias como las de Bhuvaneswari "emergen" y dejan algo, un rastro tal vez, un espectro tal vez, sobre lo cual deconstruir y construir contragenealógicamente. Tarea que debe emanciparse de la genealogía y su posible mímesis en "otros téminos", en medio de una disputa por los sentidos y las significaciones de las prácticas, donde apostamos a reescribirnos como sujetas vivas desde la aparente imposibilidad de ello y su casi seguro fracaso, en un mundo donde definitivamente: "El subalterno no puede hablar. No hay virtud en las listas globales de lavandería con la "mujer" como un artículo piadoso. La representación no se ha marchitado. La intelectual femenina como intelectual tiene una tarea circunscrita que no debe rechazar con una rúbrica" (Spivak, 2003, p. 362).

\section{Statham de La Cruz Garzón Bauer y el problema del archivo}

Toda investigación genealógica se contruye a partir de un archivo definido como un acervo de documentos que guarda cierta memoria y que es posible por un proceso institucional de clasificación y ordenamiento que le da sustento (Añón y Rufer, 2015). El archivo no se trata simplemente de un ejercicio de clasificación y resguardo de documentos escritos o digitales, sino 


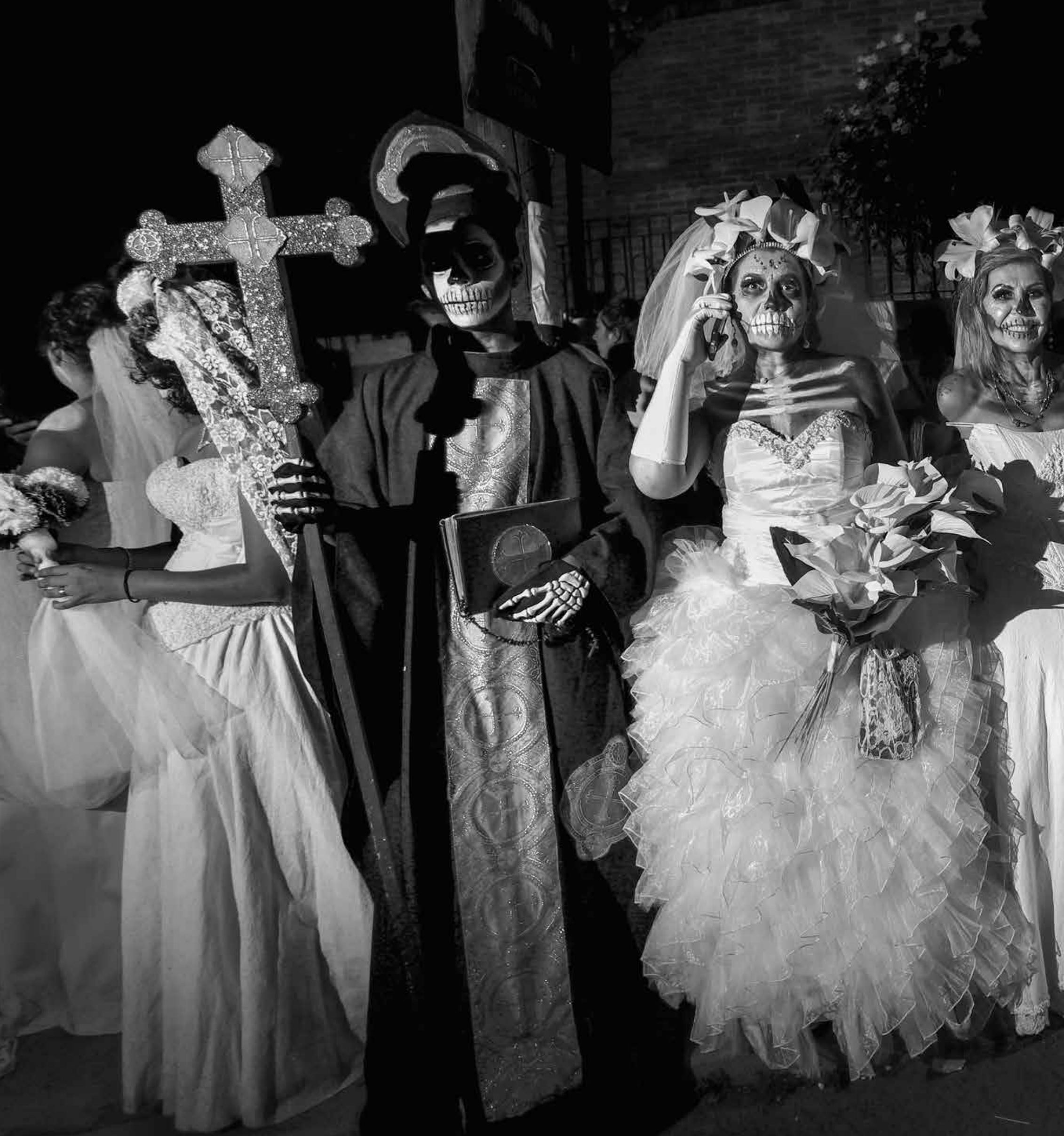




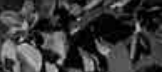

-4) 51 (3)

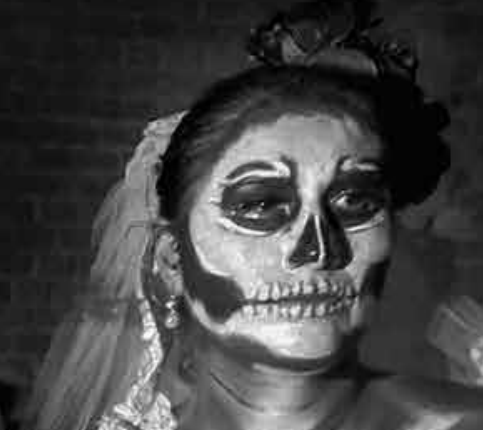

$\frac{1}{4}$ (i)

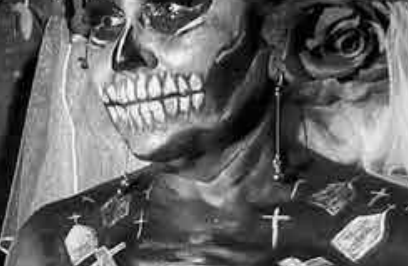

$1 \mathrm{C}^{2}$ 4. 2 Qरा1 in

10 at

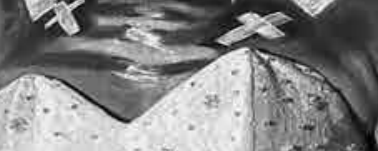
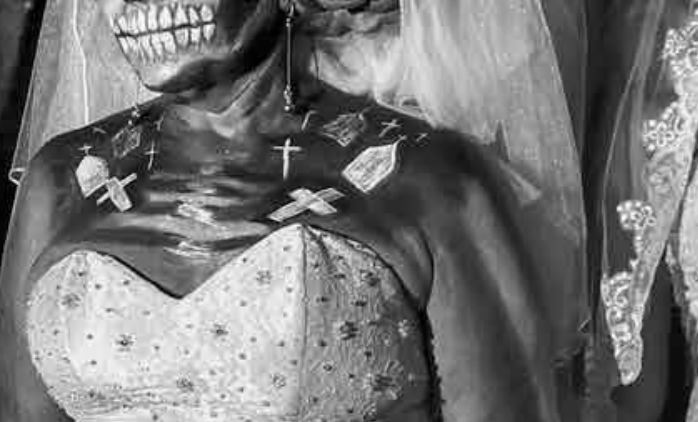
(90) (3)

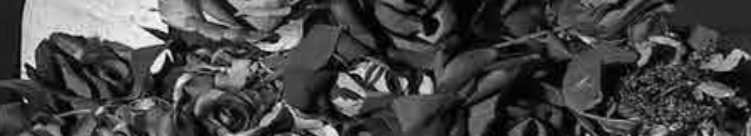

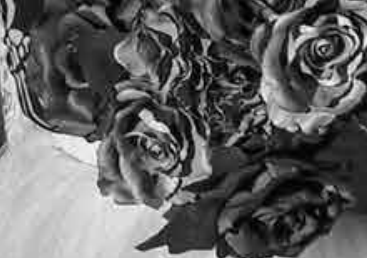




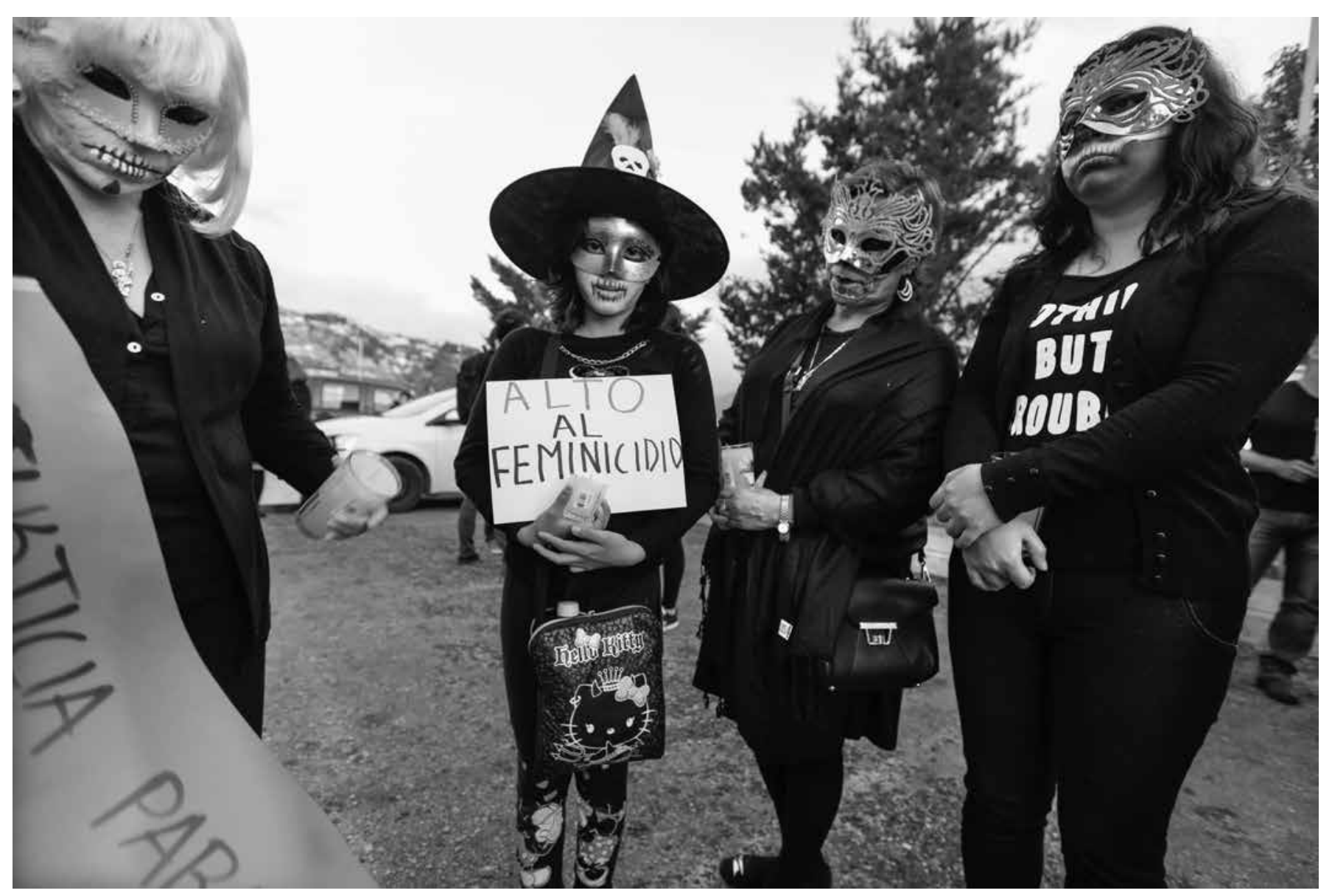

Imagen 4. Efraín Ascencio Cedillo (2017). Tlaquepaque (Jalisco, México). Cortesía del artista.

de uno de poder cuya misión es construir en su conjunto una versión de la historia que se aspira corresponda con la "verdad" y, por lo mismo, sea consagrada como la versión hegemónica, la historia única (Adichi, 2010; Bhabha, 1997). Ciertamente, la domiciliación, los enunciados autorizados, el principio de clasificación de documentos y las condiciones de su circulación son técnicas de poder. No obstante, el archivo tiene un límite que necesita ocultar para operar: en su origen debe haber un "vestigio", algo iterable que pueda ser repetido para ser naturalizado, quedar fijo y, por ende, construir la apariencia de continuidad, del acontecimiento único como principio. A esta paradoja, esta suerte de contradicción entre repetición y no repetición, Jaques Derrida la llama double bind. Por ello, los archivos batallan con su propia imposibilidad:

Un archivo debe ser a la vez único y significante. En algunos casos, tenemos que vérnosla con la huella del acontecimiento único. Pero como es un archivo, saben que lo que capten ahí de único no ha podido inscribirse como tal sino en la medida en que fuera repetible. Ya lleva su doble en sí mismo. Y no ha podido inscribirse más que sacrificando, excluyendo, reprimiendo tantas cosas que continúan habitándolo. Eso quiere decir que la firma de la primera inscripción ha sido ya un acto de archivación, incluso antes de que el archivista viniera a recolectar, asignar, establecer. $Y$ en este ejercicio de archivación, hubo un acto de poder, de selección, de violencia. Continuará siempre siendo asediado por lo que ha excluido y por su doble. Y aquí, no podemos sino multiplicar los enunciados contradictorios (2013, pp. 9-10).

Como resultado, los archivos así pensados: "lidian con la huella silenciada como su condición de posibilidad: no todo el mundo se puede traducir en un documento, no toda vida se puede atrapar en un trazo, no toda memoria está circunscrita por la institución moderna: la biblioteca, el archivo, el museo" (Garzón, 2016, p. 79). Archivo y silencio también son un double bind. $Y$ esto es fundamental porque para las mujeres, el ejercicio genealógico si es que este existe está llamado a: “interpretar también desde el olvido, las ausencias, las negaciones, las discontinuidades y los silencios. Como 
lo señala Rodríguez: Una historia de las mujeres debe compartir con la arqueología su suspicacia frente a los criterios continuistas de una Historia Global, replanteando jerarquías, teleologías u olvidos, así como las justezas de los cortes y agolpamientos temporales, incorporando los hechos decisivos en las relaciones entre los sexos" (Restrepo, 2016, p. 16). Pero ello, asegura Yuderkys Espinosa (2014), no se debe hacer ya desde la historia de las ideas de las mujeres, sino desde la historización de las prácticas feministas lo que, en últimas, no solo nos obliga a implicarnos con la historia, el contexto, la huella y la concreción de las herramientas que usamos para producir conocimiento estratégico, sino también nos obliga a una escritura "sin garantías", donde la contradicción, la contingencia y el vacío de las preguntas sin respuesta son lo que son, ni más ni menos (Rufer, 2016).

Y una vez más se arriba al problema del archivo. Esta tarde, vía Skype, Yuderkys y yo hablamos del problema sobre cómo hacer genealogía no desde documentos archivísticos, ni desde corpus canónicos, más bien desde lo que hemos experimentado en la piel y si, en últimas, nuestro reto debe entrar en la categoría de lo genealógico, en tanto la experiencia no es un archivo en términos extrictos o no lo es para la academia androcéntrica y colonial. No fue una conversación fácil, pues siempre se debe lidiar con la incertidumbre de la experimentación, la posibilidad de que todo el trabajo se vaya por una cañería al no ser tan siquiera tomado en cuenta por los que saben y los puntos ciegos de la creatividad, también porque Statham de La Cruz Garzón Bauer -mi pequeño chiguahua - demandaba juegos y mimos y no dejaba de ladrar. El ladrido irrumpe en la conversación intelectual. El cuerpo y sus experiencias retan los haceres de la producción de conocimiento y demandan ser explicados. La risa termina por descolocar los fundamentos del archivo y nos invita a trabajar con la presencia de una ausencia. Entonces, se formula la pregunta obligada: qué tipo de archivo se edifica desde la experiencia feminista cuando:

La experiencia es la que permitió la construcción de un conocimiento que rehúye y rechaza las ilusiones de la omnipotencia del conocimiento neutral y des-encarnado que quiere combatir. El conocimiento producido desde la experiencia es siempre conocimiento parcial, y por ello situado. $Y$ el conocimiento situado es el único que comporta la responsabilidad ética de su construcción. Entonces, la construcción de un conocimiento que parta de la experiencia no solo es la posibilidad de la construcción de una herramienta metodológica que permita visualizar estados de cosas inéditos para la ciencia, sino que es una herramienta que abraza simultáneamente compromisos éticos. [...] El camino de la experiencia es, por tanto, no solo el "sin-remedio" ante la ausencia de la lengua disponible en la ciencia, sino un horizonte político para la construcción de un conocimiento científico. La experiencia, como herramienta epistémica y política, fue el gran aporte, y la gran piedra en el zapato, introducida por los estudios de género [feminista] al saber académico (Trebisacce, 2016, p. 289. El agregado es mío).

La experiencia de las mujeres es aquello que el archivo ha excluido para ser posible, se puede afirmar, pero que continúa ahí. Por ejemplo, en los años ochenta y noventa del siglo pasado, en Colombia, varias críticas literarias sospechan que las escritoras son borradas del archivo, del canon literario nacional, de maneras paradójicas, ya que se les excluye como mujeres, pero a veces se les incluye como "anomalías", pies de página. Tal exclusión no es extraña si se reconoce que la historia literaria colombiana es, en palabras de la crítica Montserrat Ordóñez: "una historia con muchas versiones que en el fondo subrayan una sola: la exaltación de una literatura de y para un mundo de valores masculinos" (1987, p. 136). Entonces, la experiencia de las mujeres escritoras, sus palabras, están allí y, al mismo tiempo, no lo están. De tal contrasentido ya nos ha advertido Virgina Woolf:

Las mujeres que son representadas en la obra de Shakespeare no carecen de personalidad ni carácter, son mujeres importantes, polifacéticas, ambiciosas, inteligentes, heroicas, mezquinas, espléndidas y sórdidas pero, al mismo tiempo, las mujeres de carne, hueso y ánima son encerradas bajo llave, golpeadas, silenciadas. De estos extremos opuestos se crea un ser mixto: en el terreno de la imaginación un ser potente y, en el terreno de la práctica, un ser insignificante. Las mujeres, algunas de nosotras para ser precisa, no tienen más referente que esa paradoja y romper la paradoja implica reconstruir todo un orden simbólico donde — según lo señala Woolf siguiendo los principios de un viejo obispo- aunque los gatos tengan almas de cierta clase no es posible su arribo al cielo, así como las mujeres no pueden poseer el talento de Shakespeare. En este punto, la mujer que escribe es como el perro que baila: una figura de circo (Garzón, 2016, p. 237). 
Aquí se debe sumar algo más si vamos a construir archivos desde la experiencia: ¿Cuál es la experiencia de La Llorona, "de esa fuerza que lleva el dolor más profundo y la rabia más grande que haya existido en toda la eternidad" (The Cry, 2007)? ¿Qué debe borrar este archivo, doblemente forcluido, para ser posible? La Llorona es un espectro que se ha transformado en un personaje recurrente en la cultura popular latinoamericana, aunque en diversos contextos en el mundo entero existen entidades similares: fantasmas que gimen, se lamentan o lloran en los ríos por diferentes motivos. En nuestro territorio, La Llorona es arquetipo de la madre asesina, habitante de lagos, ríos, cascadas u otras fuentes de agua en un mundo rural, capaz de predecir vientos fuertes o tormentas, que castiga a los hombres e invita a las demás mujeres a "llorar conmigo, matar conmigo", porque ha perdido a sus hijos (Arreola, 2004). Su historia parece hallar sus orígenes en el registro de leyendas prehispánicas, pero su configuración final es producto de la ocupación imperial y la colonialidad en la Abya Yala. Por ello, porque es una traidora al parir los hijos del opresor y porque es un monstruo que ha perdido su humanidad al "matar" a esos hijos, La Llorona no puede ser inteligible ni iterable. Su lamento - "mis hijos, mis hijos" - no comunica nada, solo mata a quien lo escucha. Su experiencia es espectral, no deja marca. La Llorona es el silencio, tiene gemido, pero no voz y mucho menos adquiere un estatus dialógico.

Si es que acaso existe un archivo de La Llorona, este está constituido por las prácticas discursivas de la cultura popular que hablan en su lugar para explicar el "trauma", los efectos del "despojo", la "traición", la "sobreviviencia" y, en últimas, la "violación", el "mestizaje" y los "bastardos". Pero ese no es el archivo que busco. ¿Cómo evidenciar la huella borrada? Es posible, siguiendo a Silvia Rivera Cusicanqui, que en este caso el silencio definitivamente conforma un archivo para pensar el pasado desde la "escucha" del lamento, en el presente, que "habla de una historia viva, que pugna constantemente por irrumpir, sometida a un juego de fuerzas que la actualiza" (2010: 6). Pero ¿cómo escuchar a la Llorona sin morir, sin regalar nuestro llanto? Así, además de saber interpretar teórica, metodológica y políticamente el silencio de las subalternas, de igual manera debemos construir un contra-archivo como sustento de una contra-historia. De ahí se desprende que es preciso historizar lo que en sí mismo carece de historia propia y cuyo sustento material ya no es la sangre - como en el caso de Bhuvaneswari-, sino las lágrimas $y$, desde ahí, imaginar nuevas formas de escucha y diferentes respuestas, "pues siempre cabe otra posibilidad, por lo mismo, otro camino y otra forma de hacer el recorrido" (Garzón, 2015). Ahora bien, ¿cómo se hace esto sin caer en el double bind derridiano y en la multiplicación de los enunciados contradictorios? “¿Saber?," como decimos en Chiapas.

\section{Lamento}

La Llorona y su lamento "dicen" lamentar ponernos en tantos líos. Yo lamento no tener respuestas. En la práctica, pienso que mi trabajo intelectual, resumido en el esfuerzo de contar las mejores historias posibles al decir de Lawrence Grossberg (2009), se alimenta de la genealogía aprendida de la mano de Castro-Gómez. En algún momento, he llegado a sentir que sigo los pasos de Spivak cuando reconstruye la contra-historia de Bhuvaneswari y que es posible establecer un archivo válido, aunque problemático, desde la experiencia. En ese sentido, la genealogía de La Llorona empieza a ser soñada pensando siempre que el silencio, como el lugar en medio de las palabras, hace parte del orden colonial y de las relaciones de poder que producen la subalternidad y que, bajo esos parámetros, al igual que con el chisme, el rumor, la risa, el ladrido, el silencio puede ser analizado de alguna manera. No obstante, siempre la investigación feminista lanza preguntas y arrastra con los hábitos de pensamiento y de investigación. Y esto se debe a que los "encuentros fugaces con el otro [la otra y el sí misma] también constituyen la sustancia del análisis, pues acordarse conlleva no solamente una poética del lamento, sino además la historia de lo que vamos dejando de lado implica un "forcejeo contra el olvido". (Morris, 2017, p. 203. El agregado es mío).

Por estas razones ahora me encuentro desarmando todo lo que he armado, pues considero que erré el camino y que muy seguramente las huellas del silencio que busco no están allí donde pensé y el método a través del cual hago mis lecturas debe ser reconstruido de manera radical. Me enfrento, una vez más, al fracaso. Armar / desarmar / montar / desmontar palabras no es un juego del que se salga indemne o sin cicatrices, es una apuesta arriesgada por hacer correr la sangre sin el adiestramiento del latido afín a la utilidad y la plusvalía del ejercicio literario (Flores, 2010, p. 213). Y con esta presencia comprendo una única cosa: el silencio de La Llorona demanda ser emancipado, su contra-historia también. No obstante, si esto es así, entonces, "¿en qué dirección debemos caminar hacia el futuro?", pregunto un día a Castro-Gómez (Garzón, 2015). El genealogista no tiene la respuesta, la contragenealogista tampoco. 


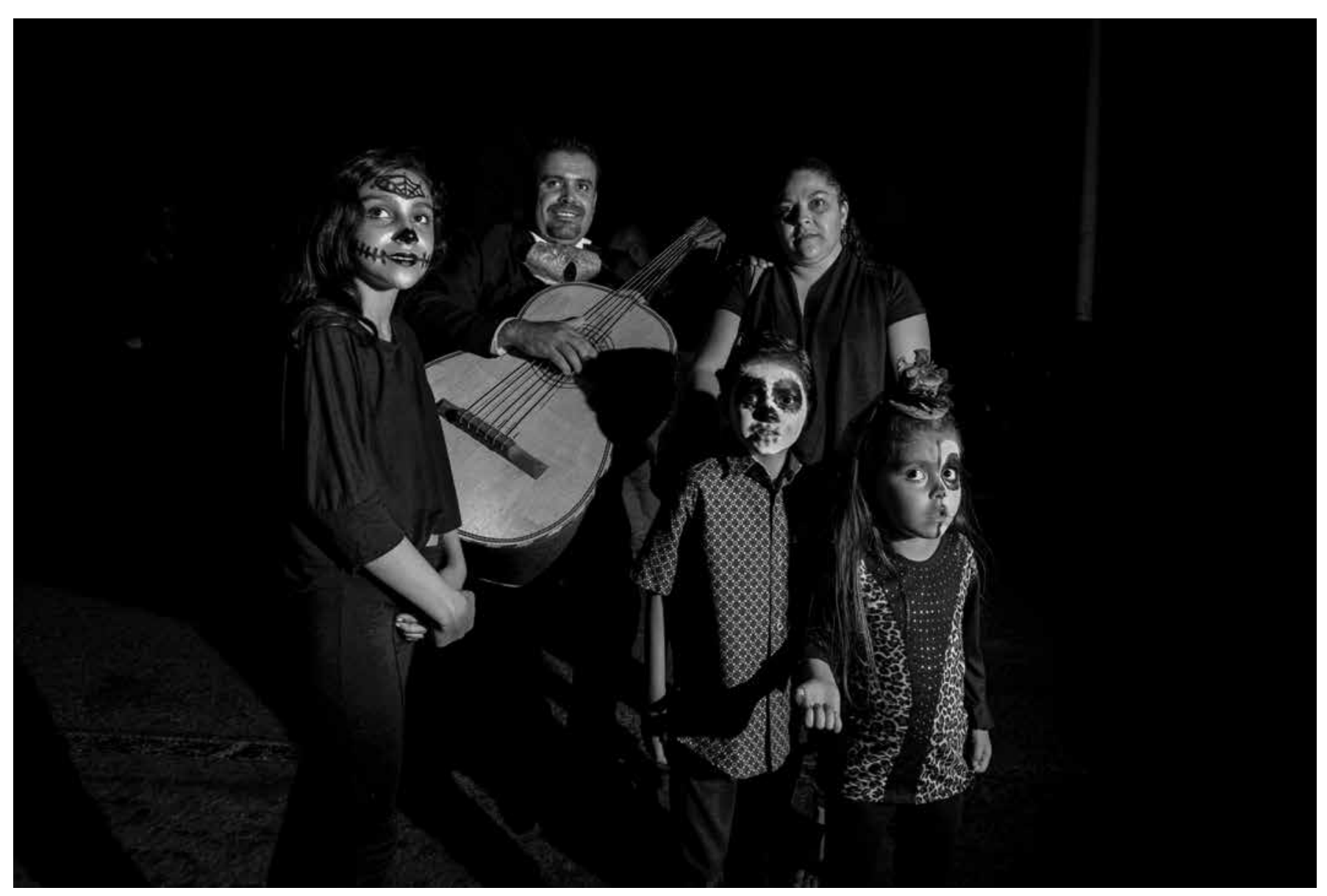

Imagen 5. Efraín Ascencio Cedillo (2017). Tlaquepaque (Jalisco, México). Cortesía del artista.

Sin embargo, esto es otra de nuestras potencias, puesto que tanto el fracaso, como la pérdida, la frustración y el miedo nos dotan de visiones y posibilidades de triunfo por más pequeñas que ellas sean o, por lo menos, aumentan nuestro umbral de dolor (Garzón, 2018). ¿La contragenealogía, sus archivos y el silencio serán entonces un imposible, el campo de lo irrealizable? Mi respuesta es no. Quiero apostar porque el silencio y su contragenealogía - que al final de cuentas son una contragenealogía del "nosotras" - no es lo irrealizable, sino una propuesta de intervención y transformación, una condición de la lucha política que se debe construir con creatividad y rigurosidad. Por ello, "nunca el silencio será tiempo perdido" como aseguró un día otro gran genealogista: Gustavo Cerati.

\section{Referencias}

Ardichie, Ch. (2010). "El peligro de una sola historia". En http://www.coachingcenter.cl/cr/ banners/20100913124050foto1.pdf [Consultado el 2 de diciembre de 2018]
Arreola Jiménez, M. (2005). Leyendas de ayer, hoy y siempre, México: IPN (Instituto Politécnico Nacional).

Añón, V.; Rufer, M. (2015). “Sesión 5: el archivo, la huella, la ruina". En Seminario virtual crítica post/ decolonial: debates en diálogo sur-sur. Clacso: Espacio de formación virtual.

Bhabha, H. (1997), “DisemiNación. Tiempo, narrativa y los márgenes de la nación moderna". En Nación y narración. Entre la ilusión de una identidad y las diferencias culturales. Argentina: Siglo XXI.

Castro-Gómez, S. (2013). "Michel Foucault: el oficio del genealogista" [video]. Disponible en <https://www. youtube. com/watch?v=033YTK-tOzo>. [Consultado el 25 de noviembre de 2018].

Derrida, J. Et al. (2013). "Archivo y borrador". En Graciela Goldchluk, Mónica G. Pené. (Comps.), Palabras de archivo. Santa Fe: Ediciones UNL y CRLA-Archivos. Disponible en https://filologiaunlp. files.wordpress. com/2012/02/archivo-y-borrador.doc 
Espinosa-Miñoso, Y. (2014). “Una crítica descolonial a la epistemología feministacrítica". En El Cotidiano, 184(marzo-abril) pp. 7-12.

Flores, V. (2010). “Escribir contra sí misma: una microtecnología de subjetivación política". En Espinosa, Y. (Coord.). Aproximaciones críticas a las prácticas teórico-políticas del feminismo latinoamericano. (1) pp. 211-230. Buenos Aires: En la Frontera.

Garzón Martínez, M. T. (2018). “Defender Fantasía: Hacia un modelo de crítica cultural feminista", ÍSTMICA. Revista de la Facultad de Filosofía y Letras. (22) pp. 79-99.

(2016). "Nunca regalé el llanto. Silencio, gemido y re(ex)sistencia en La Llorona". En: Cejas, Mónica I. Feminismo, política y cultura. Prácticas irreverentes, México: Ítaca, Universidad Autónoma de México-Xochimilco.

. (2015). "Seguir al conejo blanco: Santiago

Castro-Gómez y el oficio del genealogista". Nómadas

(43) pp. 217-229.IESCO-Universidad Central de Colombia.

Giraldo, S. (2003). "Nota introductoria”. En: Spivak, Gayatri Chakravorty, “¿Puede hablar el subalterno”, Revista Colombiana de Antropología. 39(enerodiciembre) pp. 297-364.

Grossberg, L. (2009). “El corazón de los estudios culturales: contextualismo, construccionismo y complejidad". Tabula Rasa. (10)pp. 13-48.

Hernández González, F.; Rodríguez Mora, T. (2012). "Genealogía de las herencias coloniales. Entrevista a Santiago Castro-Gómez". Andamios. 9(20), (septiembre-diciembre) pp. 187-199.
Ordoñez, M. (1987). "Elisa Muujica novelista: del silencio a la historia, por la palabra", Revista de Crítica Literaria Latinoamericana. 13(26) pp. 123-136.

Rivera Cusicanqui, S. (2010). Ch'ixinakax utxiwa: una reflexión sobre prácticas y discursos descolonizadores. Buenos Aires: Tinta Limón / Retazos.

Restrepo, A. (2016). “La genealogía como método de investigación feminista". [Ponencia] XI Congreso Iberoamericano de Ciencia, tecnologías y Género. En: https://congresoctg.ucr.ac.cr/memoria/descargar. php?id=30 [Consultado el 15 de noviembre de 2018]

Rufer, M. (2016) “El archivo: De la metáfora extractiva a la ruptura descolonial". En: Mario Rufer; Frida Gorbach. (Coord.). (In)disciplinar la investigación: archivo, trabajo de campo y escritura. México: Universidad Autónoma Metropolitana, Siglo XXI editores.

Spivak, G. Ch. (2003). “¿Puede hablar el subalterno”. Revista Colombiana de Antropología. 39 (enerodiciembre)., pp. 297-364.

Morris, M. (2017). "Banalidad en los estudios culturales". Revista Liminar. Estudios sociales y humanísticos. XV (2), pp. 181-212.

Trebisacce, C. (2016). “Una historia crítica del concepto de experiencia de la epistemología feminista". Cinta moebio. (57), pp. 285-295.

\section{Filmografía}

The Cry. (2011). Disponible en <https://www.youtube. com/watch?v=QrIaOh- dK7ng $>$, [Consultado el 17 de octubre de 2015]. 